\title{
TENSÕES ENTRE POLÍTICAS, CURRÍCULOS E EXPERIÊNCIAS INCLUSIVAS NA FORMAÇÃO DOS PROFESSORES EM SÃO GONÇALO.'
}

Anelice Ribetto

Gilcelia Coelho(*)

"O que faz falta é uma metamorfose, um acontecer." (Baudillard)

Este texto tem como objetivo dar a ver os resultados do Projeto de Pesquisa "Tensões entre Políticas e experiências inclusivas na Formação dos Professores em São Gonçalo"2 coordenado por mim entre 2014 e 2017. A pesquisa teve três objetivos principais.

O primeiro foi analisar o currículo do Curso de Pedagogia da Faculdade de Formação de Professores (FFP) da UERJ após o ano de 2006 e problematizar as lógicas e sentidos produzidos por ele com referência ao campo da Educação Especial e da Educação Inclusiva na Formação dos Professores, especificamente dos pedagogos. O segundo objetivo se centrou em cartografar práticas de professores egressos do mesmo Curso, que trabalhassem em escolas regulares com alunos com deficiências, transtornos globais do desenvolvimento e altas habilidades/superdotação, em São Gonçalo (RJ), para tornar visível e enunciar os efeitos e experiências que relacionam a formação inicial e continuada com os desafios da inclusão no cotidiano escolar. Finalmente, o terceiro objetivo foi analisar e intervir no processo formativo de alunos que participassem do Subprojeto PIBID/CAPES/UERJ do Curso de Pedagogia da FFP, através dos projetos direcionados ao estudo das diferenças em educação e das políticas e/ou práticas de inclusão escolar, tensionando os achados de pesquisa de campo com elementos teóricos e políticos do próprio Curso.

Esses três objetivos compõem um desejo de pesquisa que se tornou o objetivo central, e que foi "analisar, intervir, acompanhar e cartografar experiências formativas - na dimensão inicial e continuada - de alunos e ex-alunos do Curso de Pedagogia da FFP envolvidos com estudantes a quem se direciona a Política Nacional de Educação Especial na Perspectiva da Educação Inclusiva (BRASIL, 2008) atuando em projetos que problematizamdas diferenças em educação e das políticas

\footnotetext{
${ }^{1}$ Revião: Prof. Ms. Juan José Rodriguez (Universidad Nacional de Córdoba/Argentina).

${ }^{(*}$ Anelice Ribetto. Universidade do Estado do Rio de Janeiro - FFP. E-mail: anelatina@gmail.com.

Gilcelia Coelho. Universidade do Estado do Rio de Janeiro - FFP.

${ }^{2} \mathrm{O}$ projeto teve financiamento da Faperj a través de Bolsa de Iniciação Cientifica para aluna de graduação e de Bolsa Jovem Cientista de Nosso Estado para a coordenadora. Teve também financiamento da UERJ, a través de Bolsa de Iniciação Cientifica para aluna de graduação e Bolsa Prociencia para a coordenadora.
} 
e/ou práticas de inclusão escolar”. Usamos para tanto a cartografia como método de pesquisa. A cartografia, como proposta por Gilles Deleuze e Felix Guattari (1995), implica acompanhar processos de produção de subjetividades e intervir. Deste modo, a metodologia teve como interlocução as dezesseis pistas produzidas e organizadas por Kastrup, Passos e Escossía (2010) e por Kastrup, Passos e Tedesco (2013). Além desses interlocutores, houve a presença de Jorge Larrosa e sua ressignificação no campo da educação sobre o conceito de experiência (LARROSA, 2014) Há nesta pesquisa três conceitos que atravessam a nossa escolha metodológica: cartografia, experiência e ensaio. Junto com esses interlocutores e conceitos, as práticas de formação inicial e continuada de professores ajudaram a tornar visível e enunciar o que se passa e nos passa em formação. Cartografar. Se implicar. Experimentar. Escrever o experimentado requer ensaiar possibilidades de se dizer e se produzir.

A importância da experiência do pesquisar aponta sua inscrição no plano de forças, que
constitui o plano de produção tanto do conhecimento quanto da realidade conhecida.
Pesquisadores e pesquisados, bem como o problema da pesquisa cartográfica, estão
mergulhados na experiência. Isto afasta, muito claramente, a cartografia das metodologias de
pesquisa pautadas apenas na informação - aí incluído o procedimento denominado "coleta",
bem como o processamento e a análise das informações (KASTRUP PASSOS TEDESCO,
2013, 217).

Pesquisar se implicando, acompanhando percursos rizomáticos (DELEUZE; GUATARRI, 1995) que se apresentam pelos seus movimentos e não pelas suas categorizações estanques. Trabalhar e pensar o conceito de experiência na pesquisa (LARROSA, 2014) implica pensar uma investigação que é capaz de padecer desterritorializações, mudanças, reterritorializações e, principalmente, capaz de suportar a irrupção do acontecimento que é o que possibilita que alguma coisa -que ainda não se conhece, não se sente, não se pensa- nos passe, e, porque nos passa, nos transforme. O dilema foi como pensar os percursos metodológicos que suportem o devir: o acontecimento irrompendo e transformando a própria pesquisa. Assim, cartografa-se, experimentando deslocamentos e ensaiando a pesquisa em territórios de tensão. Para acompanhar esses processos, porém, não se pode "ter predeterminada de antemão a totalidade dos procedimentos metodológicos" (KASTRUP; PASSOS; ESCÓSSIA, 2010, p. 13) Assim, o trabalho habitou o campo problemático e acompanhou processos formativos. De início, definimos algumas frentes de ação para tal cartografia, descritas em alguns tópicos:

1) Estudo dos documentos curriculares do Curso de Pedagogia e tensionamento com Diretrizes Curriculares Nacionais do Curso de Pedagogia; 
2) Realização de entrevistas com Coordenadores do Curso de Pedagogia da FFP que tenham participado nas reformas curriculares desde 2006;

3) Realização de Entrevistas-conversas com professores egressos da FFP que trabalham com alunos com deficiências, transtornos globais do desenvolvimento e altas habilidades/superdotação;

4) Acompanhamento das aulas (em salas regulares ou sala de recursos multifuncionais); e

5) Coordenação de um grupo de estudos-extensão com professores egressos da FFP; Coordenação de grupos de estudos, planejamentos e avaliação direcionados ao estudo e problematização das diferenças em educação e das políticas e/ou práticas de inclusão escolar com alunos bolsistas de ID do Sub Projeto PIBID do Curso de Pedagogia da FFP/UERJ que atuem em projetos direcionados ao estudo e problematização das diferenças em educação e das políticas e/ou práticas de inclusão.

\section{EFEITOS (RESULTADOS) DO ESTUDO DAS TENSÕES ENTRE POLÍTICAS E EXPERIÊNCIAS INCLUSIVAS}

Uma apresentação sucinta dos principais resultados obtidos na pesquisa nestes quase três anos de projeto implica produzir um dispositivo de análise que nos permita dar a ver e falar os efeitos dos próprios movimentos que foram se produzindo ao longo deste processo. Coerente com a proposta metodológica da cartografia, este relato, apresenta o acompanhamento de um processo que foi sendo experimentado, sofrendo deslocamentos e ensaiando a pesquisa em dois territórios de tensão:

1) o Curso de Pedagogia da FFP, seu histórico de composição, seus efeitos a partir de reformulações e a atualização deste território no preciso momento em que se discute uma nova reformulação curricular a partir da Resolução 2/2015 que define as Diretrizes Curriculares Nacionais para a formação inicial em nível superior (cursos de licenciatura, cursos de formação pedagógica para graduados e cursos de segunda licenciatura) e para a formação continuada (BRASIL, 2015) e,

2) os Processos formativos iniciais e continuados de estudantes em contato com alunos com deficiências, altas habilidades e superdotação e transtornos globais do desenvolvimento (estudantes que cursam Pedagogia e professores egressos deste Curso).

No projeto inicial, definimos alguns resultados esperados, ainda que, por se tratar de uma cartografia não podíamos definir exatamente e a priori de que forma estes movimentos (chamados formalmente de resultados) se dariam e quais efeitos ele produziriam. 
Foram eles:

1) Elaboração de um estudo sistemático do Currículo de Pedagogia relacionado ao Campo da Educação Especial e Educação Inclusiva que subsidiasse as novas reformas curriculares que aconteceriam a partir de 2015 no Curso de Pedagogia da FFP;

2) Criação de um grupo de estudos com professores egressos da FFP que trabalhem em escolas regulares em São Gonçalo e localidades vizinhas com alunos com deficiências, transtornos globais do desenvolvimento e altas habilidades/superdotação com o objetivo de contribuir para a problematização das práticas e das políticas inclusivas afirmando a importância de uma formação continuada tecida entre universidade e escola básica;

3) Colaboração na ampliação de projetos que tenham como finalidade a continuidade da formação e atualização docente de profissionais egressos de FFP;

4) Coordenação de grupos de estudos, planejamentos e avaliação direcionados ao estudo e problematização das diferenças em educação e das políticas e/ou práticas de inclusão escolar com alunos bolsistas e supervisores da escola básica do Subprojeto PIBID/CAPES/UERJ do Curso de Pedagogia da FFP; e,

5) Produção e apresentação de trabalhos, textos e artigos em seminários e congressos, bem como em publicações afins, pelos componentes do projeto de pesquisa.

A seguir apresentamos brevemente alguns resultados entendidos como efeitos produzidos a partir de três movimentos de pesquisa e, vinculados aos objetivos iniciais do projeto em questão.

\section{Realização de estudos, planejamentos e avaliação direcionados ao estudo e problematização das diferenças em educação e das políticas e/ou práticas de inclusão escolar.}

Este movimento se inicia com um dispositivo metodológico específico a partir do começo de nosso projeto: a conformação de um grupo de estudos formado por alunos do Curso de Pedagogia da FFP e bolsistas e supervisores da escola básica do Subprojeto PIBID/CAPES/UERJ, que coordenei de março de 2014 a março de 2016. Os grupos de estudos e acompanhamento de projetos ligados à discussão da diferença se desenvolveram em articulação com o Sub Projeto PIBID/CAPES/UERJ do Curso de Pedagogia da FFP e aconteceram no CIEP 411 do Município de São Gonçalo. Enquanto Programa institucional, o PIBID se constitui uma macropolítica de valorização do magistério, a qual articula universidade e escola básica, levando licenciandos para escolas da rede pública de educação. O Subprojeto de Pedagogia problematiza a tensão entre a formação dos cursos de licenciatura e a vida na escola, contextualizando conceitos e preconceitos 
em torno da formação inventiva de professores, políticas da diferença e situando práticas forjadas nos cursos de Pedagogia. Trata-se de algumas experiências, produções e ações realizadas junto ao PIBID/CAPES para mostrar como as políticas da diferença e uma formação inventiva podem intervir no contexto escolar e nas políticas de formação inicial e continuada de professores.

Como coordenadora do subprojeto me encontrava semanalmente com o grupo de bolsistas e supervisoras e planejávamos nosso trabalho da seguinte forma: uma semana desenvolvíamos os trabalhos de Iniciação à Docência e Iniciação Científica junto aos alunos e professores da escola e na semana seguinte, nos encontrávamos num grupo de estudos com o objetivo de promover um exercício de pensamento sobre o experimentado no encontro. É importante dizer que o Sub Projeto conta com 30 bolsistas de ID e seis supervisoras-professoras de duas escolas parceiras e acontece desde março de 2014. No projeto inicial apontávamos que a importância para a UERJ deste movimento era reforçar a relação entre ensino e pesquisa, docência e produção de conhecimento e ampliar as instâncias formativas do Curso de Pedagogia. Este movimento se implica com os outros dois que descreveremos embaixo, principalmente com a necessidade de operar uma ampliação na criação e reconhecimento de uma rede formativa curricular especificamente no Campo de estudos da Educação Especial e Educação inclusiva ${ }^{3}$ que não se fecha na concepção disciplinar do currículo. Neste sentido entendemos o grupo de estudos e acompanhamento de trabalhos desenvolvidos pelas graduandas em Pedagogia colocando em questão as políticas e práticas da diferença como uma expansão dos espaços-tempos formativos e de produção de sentidos outros para o Campo da Educação Especial e a Educação Inclusiva.

Um dos trabalhos acompanhados e produzidos foi "Sala de Recursos Itinerante", projeto criado a partir da demanda da escola e de uma das supervisoras/professoras que se desenvolvia como professora de Sala de Recursos. Estas salas são espaços tempos localizados nas escolas regulares nas quais se realiza o Atendimento Educacional Especializado (AEE) para alunos com deficiências, transtornos globais do desenvolvimento e altas habilidades - superdotação (BRASIL, 2010) O objetivo do trabalho "Sala de Recursos Itinerante" (que durou dois anos) foi "questionar a produção da norma na escola a partir do deslocamento espacial e temporal da Sala de Recursos com o Projeto Sala de Recursos Itinerante" Na proposta inicial do AEE da escola "a sala" é um

\footnotetext{
${ }^{3}$ A Educação Especial é considerada nesse trabalho, pensando com Márcia Pletsch (2010), como sendo um campo, ou área do conhecimento, na qual se desenvolvem as políticas, práticas e teorias voltadas para a educação dos alunos com deficiência, transtornos globais do desenvolvimento e superdotação/altas habilidades. A Educação Inclusiva é entendida como um projeto político, uma proposta na qual as políticas públicas garantem não apenas o acesso a escola, mas todas as condições de permanência, desenvolvimento e adaptações necessárias ao aprendizado de cada aluno, respeitando suas especificidades.
} 
espaço-tempo estático e ela acontece, habitualmente como espaço-tempo separado, ainda que articulado, dos demais espaços-tempos escolares. O intuito do projeto foi o de produzir movimentos para que as atividades que acontecem usualmente no espaço-tempo da Sala de Recursos possam se deslocar pela escola básica como um todo: cozinha, banheiro, outras salas de aulas, corredor, pátio, horta, quadra e dessa forma se implicar nos processos escolares que todos os alunos desenvolvem, embora com as especificidades do AEE. Assim foram produzidos brinquedos adaptados para um aluno com deficiência física, livros multisensoriais para um aluno com baixa visão, contação e escrita de histórias com gestos e desenhos e um grande leque de atividades que ao longo destes dois anos foram produzidas como efeitos dessas experiências e cartografadas e acompanhadas nas reuniões quinzenais do grupo de estudos 4

O conceito central que atravessou as reuniões e os trabalhos durante os dois anos foi o conceito de "experiência", longamente trabalhado por Jorge Larrosa a partir do texto clássico Notas sobre a experiência e o saber da experiência (2014), no qual o autor atrela o sentido de experiência e formação: a formação pode ser pensada como uma experiência. Segundo o autor, a experiência é "o que nos passa, o que nos acontece, o que nos toca" (p.21). Por vezes confundimos vivências com experiências e citamos fatos que ocorreram em nossa vida como experiências, quando esses fatos apenas geraram lembranças arquivadas, que pode ser acessado quando necessitamos de alguma informação sobre o assunto. Nesse sentido, Larrosa já aponta que a informação pode ser considerada uma das coisas que mais empobrece a possibilidade de experiência, pois segundo o autor, "ela não deixa lugar para a experiência" (p. 21). Isso acontece, segundo o autor, porque para que a experiência aconteça, precisamos

parar para pensar, parar para olhar, parar para escutar, pensar mais devagar, olhar mais devagar, e escutar mais devagar; parar para sentir, sentir mais devagar, demorar-se nos detalhes, suspender a opinião, suspender o juízo, suspender a vontade, suspender o automatismo da ação, cultivar a atenção e a delicadeza, abrir os olhos e os ouvidos, falar sobre o que nos acontece, aprender a lentidão, escutar aos outros, cultivar a arte do encontro, calar muito, ter paciência e dar-se tempo e espaço (IBIDEM, p. 24)

O que colocamos em análise junto com as professoras e alunas não foi apenas o que passou como fato específico na Sala de Recursos Itinerante mas aquilo que como experiência atravessou e modificou, produzindo uma (trans)formação em nós a partir do trabalho entre alunos da sala e professores. A experiência neste sentido se vinculou ao plano dos afetos e produziu um exercício de

\footnotetext{
${ }^{4} \mathrm{O}$ detalhe desde trabalho pode ser consultado em: RIBETTO, A. e DIAS, Rosimeri. Relatório Anual de Atividades do Sub Projeto PIBID/CAPES/UERJ do Curso de Pedagogia da FFP. Relatório de Pesquisa. 2014.2015 (disponível abertamente se requisitado à CAPES).
}

Revista Teias v. 18, n. 50, 2017 (Jul./Set.): Conversas sobre formação de professores, práticas e currículos 
alteridade quando as alunas sentiam coisas que nunca tinham sentido, pensaram coisas que nunca tinham pensado, perguntaram coisas para as que ainda não tinham respostas. No próprio planejamento das atividades tensionamos a necessidade de produzirmos o encontro pedagógico desde aquilo que "não sabemos do outro" quer dizer, desde aquilo pelo qual nos perguntamos ainda. Por ex. em um dos encontros o grupo manifestou o desejo de produzir um livro "adaptado para um aluno com baixa visão" como se existisse "um" livro e "uma" forma de viver a baixa visão. Toda a discussão rondou sobre a importância do encontro pedagógico como espaço de abertura e acolhimento para o que ainda não sabemos do outro e como espaço de construção da singularidade: após nos encontrar com o sujeito, de nos relacionar com o sujeito, de saber de quais materiais gosta, de quais não gosta, com qual lateralidade enxerga, conhecer os desejos, os medos, as resistências, etc. só neste momento posterior posso pensar na produção do livro, ou seja, no saber instrumental. A grande questão que o projeto levantou é que a formação é uma grande rede, na qual diferentes linhas são necessárias mas que só teremos acesso a elas se estivermos abertos para experimentar o encontro com o outro como singularidade que não pode ser apressada pela lógica da normalização e padronização. Neste sentido, os saberes didático-instrumentais, os saberes do campo jurídico, os saberes do campo do planejamento pedagógico são necessários, mas eles só entram para compor a rede após a produção do encontro pedagógico com o outro: os saberes que vêm da ética do encontro.

Por outro lado, a expressão das atividades e seus efeitos permitem enunciar as ações em curso quanto às análises micropolíticas da escola básica e da formação inicial e continuada de professores, na perspectiva da formação inventiva de professores e das políticas da diferença. Na licenciatura em Pedagogia, exemplifica-se, o diferencial qualificador do graduando que experiencia aprendizados na articulação entre universidade e escola básica e que pensa e forja práticas no interior da escola e de produções acadêmicas referentes aos movimentos que atravessam a formação inicial entre estas duas instituições. A produção dos projetos na escola tem proporcionado aos bolsistas colocarem em discussão seus modos de pensar e de fazer a pedagogia na medida em que colocam em análise e intervém nas práticas instituídas e instituintes na Licenciatura de Pedagogia, que toma corpo nos projetos desenvolvidos.

O contato com os referenciais das políticas da diferença e da cartografia tem provocado nos bolsistas e nos supervisores uma ampliação das escolhas éticas, estéticas e políticas de fazer a vida e a formação na escola básica e a universidade. Esta questão, fundamental no projeto de pesquisa, se articula e implica com o movimento a seguir que dá a ver a produção do currículo do curso de Pedagogia da FFP e seus efeitos formativos. 


\section{O curso de Pedagogia da FFP, seu currículo e seus efeitos formativos.}

Este movimento teve como objetivo traçar um breve histórico da formação de professores e do Curso de Pedagogia no Brasil, a discussão da formação de professores no campo da Educação Especial e da Educação Inclusiva no próprio curso e a atualização desta história, no presente, do Curso de Pedagogia da Faculdade de Formação de Professores da UERJ.

O objetivo da realização deste estudo foi promover a sistematização dos campos de estudos objeto deste projeto (Ed. Especial e Ed. Inclusiva) para entender os efeitos formativos do próprio currículo do Curso na formação inicial dos estudantes e as implicações na prática formativa de egressos do Curso. Por outro lado, a sistematização deste estudo ${ }^{5}$ colaborou com o debate em diversas instancias de discussão ${ }^{6}$ - a partir de contornos históricos, políticos e pedagógicos- da presença efetiva dos campos da Educação Especial e da Educação Inclusiva na proposta de Reforma Curricular em curso. Contornos que entendemos como sendo "linhas" que compõem um campo de forças que entendemos como

um território de multiplicidades de todos os tipos, de disseminação de saberes diversos, de encontros "variados", de composições "caóticas", de disseminações "perigosas", de contágios "incontroláveis", de acontecimentos “insuspeitados". Um currículo é, por natureza, rizomático, porque é território de proliferação de sentidos e multiplicação de significados (PARAÍSO, 2010, p. 587)

Para isso foram utilizados os seguintes procedimentos: estudo dos marcos jurídicos do campo, revisão de bibliografia e conversas com pessoas que participaram dos processos de construção do Curso de Pedagogia da FFP, rodas de conversas com estudantes para discussão dos sentidos da formação: contamos uma história pouco contada de forma sistematizada, a história do Curso de Pedagogia da FFP, texto que foi sendo construído ${ }^{7}$ no entre de muitas conversas, poucos documentos e umas lacunas que nos deram pistas destas linhas múltiplas das quais falamos.

Para este texto escolhemos apresentar apenas uma parte do texto do estudo realizado, aquele que nos permite fazer uma relação direta a partir da implicação através de narrativas de formação com o próximo movimento de pesquisa, que podemos chamar de III. Os estudantes egressos da FFP e a formação para trabalhar no campo da Educação Especial e a Educação Inclusiva. Este movimento implicou no contato com 10 estudantes formados na Faculdade de Formação de

\footnotetext{
${ }^{5}$ Estudo que ainda está em andamento.

${ }^{6}$ Seminários do Curso de Pedagogia, Reuniões de professores para discussão da proposta curricular e produção de documento, etc.

${ }^{7}$ RIBETTO, Anelice. O Curso de Pedagogia da FFP e a Formação de Professores para atuarem nos campos da Educação Especial e Educação Inclusiva. Documento de pesquisa. FFP, São Gonçalo, 2015;
} 
Professores e que atualmente trabalham no campo de estudos e a realização de uma cartografia das implicações na produção de sua formação inicial e continuada, revelada a partir das narrativas de formação dos próprios egressos.

Para colher essas narrativas produzimos entre 2015 e 2016 o Curso de Extensão (aprovado pelo DEPEXT-UERJ) "Professores formados na FFP e inclusão: entre políticas, práticas e poéticas”. Com uma duração de 120 horas, os objetivos deste Curso foram: 1) Cartografar -a partir das oficinas de extensão- práticas de professores egressos do Curso de Pedagogia da FFP que trabalhem em escolas regulares com alunos com deficiências, transtornos globais do desenvolvimento e altas habilidades/superdotação, em São Gonçalo e localidades vizinhas, para tornar visível e enunciar os efeitos e experiências que relacionam a formação inicial e continuada com os desafios da inclusão no cotidiano escolar; 2) Oferecer um espaço de discussão, conversa e informação aos alunos do Curso de Pedagogia da FFP e aos professores da rede de São Gonçalo e Itaboraí sobre diferentes dimensões do campo da educação especial e inclusiva a partir da exposição das experiências dos colegas (que já foram alunos da FFP). A ação de extensão esteve direcionada principalmente aos bolsistas do Subprojeto PIBID/CAPES/UERJ, estudantes do Curso de Pedagogia e professores da Rede de Itaboraí e São Gonçalo. Inscreveram-se 45 pessoas e formaram-se 30 participantes, a maioria deles alunos do Curso de Pedagogia da FFP e professores da rede de São Gonçalo e Itaboraí que desenvolvem funções como "professores mediadores ou professores de apoio especializado".

O Curso se organizou em doze encontros (oito em 2015; e quatro em 2016) e cada um deles foi coordenado por um egresso, apresentando uma narrativa formativa do trabalho que desenvolve no campo de estudos- e uma articulação desta narrativa com conceitos produzidos no próprio percurso formativo. Os encontros foram assim organizados: 1) O discurso legal (Gilcélia Coelho), 2) políticas e práticas entre escolas e hospital (Vannina Silveira), 3) Entre as línguas (Danielle Macedo e Giselly Peregrino), 4) Ver e não Ver (Leidiane Macambira), 5) Práticas de mediação com pessoas cegas (Gabrielle Macedo), 6) Poética do Encontro (Luan Savio), 7) Mediações (Taís Franca e Vanelize Cirino), 8) Medicalização e Escola (Bruna Pontes), 9) famílias e deficiências (Rejane Nascimento) e 10) a invenção na sala de recursos (Valéria Vilhena). Houve uma conferência de abertura (coordenadora do Curso) e uma conferência de fechamento (com o convidado Prof. Dr. Carlos Skliar/FLACSO/Argentina).

Este Curso deu os elementos analíticos para pensarmos o próprio Currículo do Curso e os efeitos nas práticas dos egressos. Entendemos o Curso de Extensão como um dos efeitos dos movimentos instituintes no Curso de Pedagogia que possibilitou a ampliação de espaços de 
formação dos campos da Ed. Especial e Ed.Inclusiva, e, dispositivo fundamental desta pesquisa. Consideramos este espaço como um dispositivo que ajudou a visibilizar os próprios movimentos do campo de estudos na faculdade e em relação aos municípios vizinhos (o curso foi direcionado a alunos da FFP, professores da rede de ensino de Itaboraí e São Gonçalo) e, fundamentalmente, que deu a ver o efeito da formação de professores nas práticas profissionais dos egressos participantes deste curso.

Assim, este espaço é considerado -neste trabalho- como um cenário de construção e revelação de narrativas de formação que nos permitem a posta em contato com nossos parceiros de pesquisa (egressos).

As narrativas dos egressos em cada um dos encontros constituem um diferencial neste trabalho, pois através delas, recriamos e damos outros sentidos às histórias de formação e com isso, às práticas docentes, "São as experiências formadoras, na força do que nos atinge, que nos sobrevêm, nos derrubam e transformam, inscritas na memória, que retornam pela narrativa não como descrição, mas como recriação, reconstrução" (BRAGANÇA; VELLOSO, 2011, p. 159)

Os encontros com egressos se ampliaram para a produção de outro dispositivo metodológico de pesquisa que atualmente está operando: uma roda de conversa que acontece cada dois meses e que reúne alunos da graduação e outros egressos e que problematiza os encontros pedagógicos no cotidiano escolar. Realizamos apenas duas rodas e pensamos que ainda podem acontecer outras duas, até o final do projeto.

Pensamos que a pesquisa numa ação articulada conseguiu implicar os três movimentos citados: por um lado, atuando na ponta, ou seja, produzindo "o chão da escola" junto com graduandos e egressos insertos, como professores, em escolas públicas que trabalham com alunos com deficiências, altas habilidades/superdotação e transtornos globais do desenvolvimento, e na produção desse chão a criação de dispositivos que permitam tensionar conceitos, instrumentos e práticas.

Por outro lado, atuando junto com dez egressos do Curso de Pedagogia da FFP que "voltam" para discutir, a partir de suas narrativas de formação, os sentidos da proposta curricular do Curso de Pedagogia que os formou e ajudando a produzir material que subsidie as reformulações necessárias (2015/2016). Curso de pedagogia este, que está formando os alunos graduandos que participam do primeiro movimento. É importante também dizer, que desses dez egressos, cinco voltaram como Mestrandos em Educação do Programa de Pós Graduação, Processos Formativos e Desigualdades Sociais da FFP/UERJ com projetos de pesquisa vinculados ao campo da Educação Especial e 
Educação Inclusiva, ou seja, dando continuidade a um processo formativo que os produz e que eles produzem e que tem como efeito sua volta para a escola básica e a própria universidade.

Neste sentido o Projeto de Pesquisa mostra como resultado uma grande rede formativa que atravessa a Universidade e a Escola Básica e produz sentidos para pensar e criar outras articulações possíveis entre estas no Campo de Estudos que nos ocupa.

Assim, implicamos os três movimentos escrevendo um texto no qual as narrativas dos egressos (que já foram alunos de graduação do Curso de Pedagogia da FFP) interpelam os próprios contornos históricos, políticos e pedagógicos do Curso de Pedagogia da FFP a partir de uma afirmação que escutamos naturalizada que escutamos frequentemente nos discursos de muitos estudantes e professores com os quais nos encontramos neste projeto: "não estamos preparados para trabalhar com esses alunos" e que nas três instancias de produção dos movimentos de pesquisa (alunos do curso bolsistas do PIBID, currículo do Curdo e egressos do Curso) apontamos como frase "motora" de problematizações teóricas, políticas, éticas.

SKLIAR (2011) diz que precisamos revisar qual é a pergunta sobre inclusão, cuja resposta é: “não estamos preparados". Para além de responder a essa questão de estar ou não preparado/formado passamos pela necessidade de compreensão dos sentidos que fazemos no cotidiano da escola, sobre qual tipo de formação seria a que nos prepararia. Pregunta Skliar: “ ¿Que puede significar la expresion "estar preparados” o "no estar preparados”? ¿Que puede entenderse de esa afirmación a propósito de un supuesto "saber que hacer" ante cada niño, ante cada cuerpo, ante cada lengua, ante cada aprendizaje, ante cada forma de estar en el mundo?" (p. 160) Como podemos antecipar o que fazer diante de cada estudante, antes mesmo de conhecê-lo? Existem técnicas que deem conta de nos preparar para atender cada um e qualquer sujeito? Longe de dizer que não precisamos estudar, conhecer mais sobre os mais variados assuntos relacionados ao campo da Educação Especial, podemos talvez repensar se apenas isso vai nos dar condição de saber tudo que precisamos saber sobre todos. Como então afirmar que estou ou não preparada sem fazer desta questão uma questão plesbicitária que se responde rapidamente com um sim ou um não? Partindo dessas perguntas, Skliar aprofunda os sentidos possíveis para a condição de ser/estar professor de alunos com deficiência, e porque não dizer, de todos os alunos, quando diz que "pessoalmente, ele acredita que é impossível o saber, o sentir-se e o estar preparado para aquilo que pode vir”. O que seria então relevante refletirmos sobre isso? 
Neste sentido a pesquisa da mestranda Gilcélia Coelho, ${ }^{8}$ egressa do Curso de Pedagogia da FFP, produzida no Programa de Pós-Graduação em Educação, Processos Formativos e Desigualdades Sociais da FFP/UERJ nos permite articular algumas questões quando afirma com Skliar uma possibilidade

Más que estar preparados, anticipados a lo que vendrá, que nunca sabemos qué es, de lo que se trata es de estar disponibles y ser responsables. La idea de disponibilidad y responsabilidad es una idea claramente ética, claro está, estoy disponible para recibir a quien sea, a cualquiera, a todos, a cada uno. ¿Cuál es, entonces, el problema? ¿Por qué, como docentes, no se puede ser responsable y estar disponible a que alguien, independientemente de su lengua, de su raza, de su religión, de su cuerpo esté aquí? ¿Por qué no podría, en cambio, estar disponible y sentirse responsable? (Ibidem, p. 160).

E apresenta articuladamente as narrativas colhidas no curso de extensão:

Danielle e Gisely são egressadas da FFP. Trabalham no INES (Instituto Nacional de Educação de Surdos) e foram buscar capacitação em Libras (Língua Brasileira de Sinais) após ingressar no instituto. Nada sabia dela. "Tecnicamente" nenhuma das duas estava "preparada" para trabalhar com alunos surdos que se comunicavam pela Libras.

Danielle cursou Biologia e cursou a disciplina Educação Especial como eletiva. Movida por uma situação vivida em sala de aula com um aluno surdo, ela decide buscar... Danielle conta que não teve "formação adequada" durante a graduação e então decidiu ampliar seu conhecimento cursando mestrado. "Eu dava aula normalmente e não tinha nenhuma interação com aquele aluno." "Não lembrava o nome dele e escrevi toda dissertação sem lembrar, após entregar o texto, lembrei. Era Jorge!!”. Quando ingressou no INES, se viu compelida por sua ética profissional a aprender Libras. "Eu usava o interprete como se fosse apenas um instrumento pedagógico", "Senti que precisava aprender Libras para me comunicar com meus alunos. Eram meus alunos" Danielle me lembra Soligo", quando diz que "só as crianças podem nos ensinar quem são e, às vezes, também quem somos. Alguns alunos nos arrastam para uma luta feroz a favor de um destino melhor para eles." Giselly nos conta que não teve nenhuma oferta de disciplinas na área nem na graduação, nem no mestrado. Quando foi aprovada no concurso do INES, imediatamente começou a busca pela formação que até o momento acreditava não possuir. "Nada deu preparo - preparo sistematizado -, para prática pedagógica com alunos surdos." Nesse momento da mesa, Giselly compartilha das suas angústias: precisamos de formação para trabalhar com alunos com deficiência. Essa fala remete a tudo que venho estudando, buscando: que formação seria considerada adequada? Quando posso me considerar formada? Apenas a inclusão de disciplinas garante essa formação? Danielle e

\footnotetext{
${ }^{8}$ Pesquisa em andamento intitulada "Formação de professores e Educação Especial: uma implicação narrada por pedagogos egressos da FFP/UERJ" e orientada pela Prof. Dra. Anelice Ribetto.

${ }^{9}$ Texto postado no blog de Rosaura Soligo intitulado: "Todo professor, todo aluno". Disp.: 〈https://rosaurasoligo. wordpress. com/2015/05/20/todo-professor-todo-aluno/>. Acesso $11 \mathrm{dez} .2015$.
}

Revista Teias v. 18, n. 50, 2017 (Jul./Set.): Conversas sobre formação de professores, práticas e currículos 
Giselly não se sentiam preparadas para trabalhar com esses alunos e foram procurar outros espaços formativos. Mas foram buscar fazendo... na prática.

(Narrativa sobre o segundo encontro do Curso de Extensão, chamado "Entre Línguas"- abril 2015)

Mais que estar preparado, estar disponível e se sentir responsável. Estar aberto ao encontro e nele, com sensibilidade, se esforçar para perceber quais as necessidades do aluno e quais necessidades do professor e da escola. Então eu não preciso buscar formação acadêmica, bastaria estar disponível? Essa seria uma receita mágica? Minha resposta, que na verdade é apenas um exercício de pensamento, diz que não. Não existem receitas mágicas, existem possibilidades sugeridas por um ou outro autor, experiências ensaiadas nos encontros, e elas nos ajudam a produzir nossa própria reflexão: Ser/estar atento, disponível, sensível, são escolhas minhas. (Narrativa sobre o primeiro encontro do Curso de Extensão, chamado "Políticas e práticas inclusivas" março 2015)

Luan é graduado em Pedagogia pela FFP em 2012 e seus estudos durante a graduação não focavam no campo da Educação Especial. Seu encontro com Pedro -um aluno com laudo de autismo- foi a primeira experiência com alunos com deficiência e com a profissão de professor mediador. Pedro despertou em Luan a sensibilidade e atenção que naquele momento era necessária para que o professor mediasse o aluno. Rapidamente ele percebeu que essa mediação era uma via de mão dupla, pois nesse processo, ele também era mediado por Pedro. Ele conta que foi buscar na legislação as atribuições do professor mediador e pouca coisa encontrou. Existiam brechas na Leis, mas, ao invés dessa falta paralisar suas ações, ela o impulsionou a se reinventar como professor e ele diz "Que bom que não tem nada na lei, assim eu posso inventar". A possibilidade de trabalho com esse aluno foi ampliada a partir do olhar atento desse professor, que percebeu nas fragilidades, potências.

Luan contou que na época seu pagamento era efetuado pelos pais, uma prática habitual em algumas escolas particulares. Apesar de nessa época a legislação não apontar inequivocamente que os pais não devem pagar por esse serviço a parte da mensalidade escolar, os órgãos reguladores e a justiça tem apresentado uma interpretação da lei que restringe esse tipo de pagamento, como podemos constatar em algumas notícias publicadas no site do Procon/RJ ${ }^{10}$. (Narrativa sobre o quinto encontro do Curso de Extensão, chamado "Poêticas do encontro" outubro 2015)

E continua: desde janeiro de 2016 quando entrou em vigor a Lei Brasileira de Inclusão da Pessoa com Deficiência (Estatuto da Pessoa com Deficiência) conhecida como LBI, essa cobrança é dada claramente como ilegal (art. 28. $§ 1^{\circ}$ ). Às instituições privadas, de qualquer nível e modalidade de ensino, aplica-se obrigatoriamente o disposto nos incisos I, II, III, V, VII, VIII, IX, X, XI, XII, XIII, XIV, XV, XVI, XVII e XVIII do caput deste artigo, sendo vedada a cobrança de

\footnotetext{
${ }^{10}$ Disp.: $\langle$ http://www.procon.ri.gov.br/index.php/publicacao/detalhar/1425>. Acesso em 28 jan. 2016.
}

Revista Teias v. 18, n. 50, 2017 (Jul./Set.): Conversas sobre formação de professores, práticas e currículos 
valores adicionais de qualquer natureza em suas mensalidades, anuidades e matrículas no cumprimento dessas determinações. (BRASIL. 2015a)

Tanto Vannina quanto Luan trazem questões para refletirmos no que se refere a questão legal do campo da Educação Especial. Vannina com sua luta para reformular as leis do município que trabalha e Luan quando nos conta que a falta de normatização legal no campo -no que se refere ao professor de apoio- o deixou livre para usar sua criatividade. Carlos Skliar (2001) já nos apontava sobre a necessidade que temos, enquanto professores, de ter uma lei que determine o que, como e quando fazer nosso trabalho. Ele diz que consideramos a leis como o um "fundamento principal" das mudanças no que concerne a inclusão. Sempre ouço dos professores que quando nos vemos diante de qualquer novo desafio, precisamos buscar por âncoras que nos fundamentem, pois somente assim, fundamentados legalmente, teremos nossa prática educativa respeitada e validada. Podemos pensar juntos a partir do que nos coloca Skliar:Sem querer ignorar a importância da produção técnica das secretarias de educação e/ou dos organismos internacionais, sou da opinião que as mudanças textuais poderiam ser mais bem entendidas como pontos de chegada das transformações pedagógicas e não como pontos de partida. (SKLIAR. 2001. p. 12) (Narrativa sobre o quinto encontro do Curso de Extensão, chamado "Poêticas do encontro" outubro 2015)

A maioria dos egressos participantes entrou no curso de Pedagogia posteriormente ao ano de 2006, ano em que, após muitas reformas na grade curricular, a FFP introduziu a disciplina Educação Especial como obrigatória para o curso de Pedagogia. Porém, tentando acompanhar os debates ocorridos no interior dos encontros nos seminários ${ }^{11}$ do Departamento de Educação que sinalizavam para a emergência de incluir essa disciplina em todos os cursos oferecidos pela FFP, abriu-se a opção para que os alunos das demais licenciaturas a cursassem como eletiva. Assim funciona até o fechamento deste texto. Acompanhamos alguns desses debates que diziam respeito ao campo da Educação Especial, como por exemplo, a obrigatoriedade da inclusão da disciplina Libras. Já existia na época uma lei, o Decreto $n^{\circ} 5.626$, de 22 de dezembro de 2005 (conhecida como Lei de Libras) que determinava a inclusão dessa disciplina em alguns cursos, dentre eles os cursos de formação de professores.

Eu cursei Pedagogia quando a disciplina Educação Especial já era componente da grade curricular e tive oportunidade de participar de muitos espaços formativos dentro da própria FFP, como cursos de extensão, a disciplina Libras (eletiva) grupos de pesquisa entre outras coisas. Estava tudo à minha mão, bastava ter desejo e participar. E como contei na primeira parte desse texto, eu aproveitei intensamente quase tudo que me foi possibilitado.

Após terminar o curso de Pedagogia, trabalhei em uma escola particular por um ano até ser convocada para o concurso de Estado do Rio de Janeiro onde leciono as disciplinas

\footnotetext{
${ }^{11}$ Encontros que aconteciam de tempos em tempos para discutir o curso de Pedagogia.
}

Revista Teias v. 18, n. 50, 2017 (Jul./Set.): Conversas sobre formação de professores, práticas e currículos 
pedagógicas para o curso normal (formação de professores). Minha última turma nessa escola particular tinha um aluno com síndrome de Asperger ${ }^{12}$ e quando tive que deixar a escola, passei uma semana acompanhando a nova professora para amenizar a transição já tão dura para os alunos. A primeira coisa que ela me perguntou foi: "você tem material sobre Asperger? Preciso conhecer mais dessa síndrome.” Minha resposta, imediata e meio ríspida, confesso, foi: "Você precisa conhecer mais o Renato. Nele você vai encontrar tudo que precisa para trabalhar." Ainda nos debatemos em meio à surpresa: opa! Tem um aluno com deficiência na minha turma! Essas situações me movem a continuar pesquisando, trabalhando. Me movem a continuar a busca. Hoje tenho mais perguntas que respostas. Mais dúvidas que certezas. Quando sugiro refletir, pensar sobre a prática docente, talvez devesse na verdade sugerir descompor o pensamento, como Skliar (2012, p. 71) nos propõe: "Descompor o pensamento, para acabar com os bons e com os maus pensamentos. Para acabar com os pensamentos disciplinados e com os disciplinares."

Vannina teve outro tipo de formação. Na época que cursou Pedagogia -na FFP como eu- ainda não existia a oferta da disciplina Educação Especial. Ela com seu desejo, buscou outros espaços e, quando participava do grupo de pesquisa "Processos de Interação entre Crianças e Animais: Algumas Contribuições para o Desenvolvimento Infantil”, da professora Vanessa Breia, fez uma disciplina chamada "Tópicos Especiais" na qual participou das discussões para elaboração da ementa naquele momento, pois nessa disciplina cada professor poderia escolher o tema das aulas, e assim a professora Vanessa Breia ministrou as aulas com o tema Educação Especial. Além dessa disciplina cursou outra com a professora Monique Franco na qual trataram de Educação de alunos surdos. A oferta de disciplinas não pode determinar o tipo de formação, mas nossa busca pessoal sim.

Após a conclusão do curso, Vannina foi trabalhar na Rede Municipal de Itaboraí como professora regular e após algum tempo nessa função foi trabalhar como professora de apoio em um hospital (classe hospitalar). Desejando prosseguir com seus estudos no campo da Educação Especial, ela iniciou o mestrado. Vannina não teve na graduação algumas disciplinas que hoje compõe o currículo, como Educação Especial e Libras - que são voltadas especificamente para o campo - disciplinas essas que esperamos cursar para que nos "forme", nos "prepare" para a sala de aula. A sua busca pessoal, sua sensibilidade vem fazendo a diferença na sua formação. Sobre o trabalho na classe hospitalar, diz: "Fui experimentando..." Como Dias, Vannina experimenta: É preciso experimentar e praticar uma aprendizagem de adultos. A chave de uma aprendizagem de adultos não se encontra nos anos nem no acúmulo, mas no aumento do nível de suportabilidade e no grau de abertura para experienciar os movimentos e com isso criar novos contornos que não existiam de antemão. (DIAS, 2011, p. 255) (Narrativa Gilcélia Baptista sobre primeiro encontro chamado "O Discurso Legal"- do Curso de Extensão- FFPmarco de 2015)

${ }^{12}$ A Síndrome de Asperger é um transtorno neurobiológico enquadrado dentro da categoria de transtornos globais do desenvolvimento. Disp.: 〈http://www.minhavida.com.br/saude/temas/sindrome-de-asperger〉.

Revista Teias v. 18, n. 50, 2017 (Jul./Set.): Conversas sobre formação de professores, práticas e currículos 
Gilcelia afirma que a discussão do campo da Educação Especial e da Educação Inclusiva no curso de Pedagogia ultrapassa os limites do currículo pensado apenas como uma série de disciplinas/cursos e atravessa todo o curso de forma diferente para cada aluno e professor. Se for apenas isso, poderíamos dizer que a Reforma Curricular de 2006 apenas institui a Educação especial como Disciplina Obrigatória do Curso e Libras, como eletiva. Discutir o currículo é estabelecer um plano de ideias que nos possibilite pensar que, para além dos debates sobre a inclusão de algumas disciplinas, esse campo já compunha o curso de Pedagogia de formas variadas.

Antes da reforma curricular de 2006 e desde a primeira versão do currículo, já existia a disciplina Tópicos Especiais na qual os professores decidiriam a ementa a ser dada naquele semestre letivo. As professoras Vanessa Breia, Rosimeri Dias e Monique Franco, ofereceram espaços de debates sobre o campo aproveitando a "ementa livre", produzindo assim uma brecha, uma linha de abertura para os estudos do campo. Existia também uma disciplina eletiva chamada Psicomotricidade que abordava questões da Educação Especial. Além das disciplinas, e mais fortemente a partir de 2009- os grupos de pesquisa e de estudo, os cursos, os seminários, as palestras, faziam e ainda fazem parte dessa rede que talvez possamos chamar de rede formativa e que expressa rizomaticamente por fora dos espaços oficiais (as disciplinas): encontros, grupos, coletivos, lutas, abaixo assinados pela acessibilidade ao campus, conversas com pessoas com deficiências, organização de cursos de extensão, assessoramento a instituições de fora da Universidade (Conselhos Municipais de Educação, Coordenação de Educação Especial, etc) e, principalmente, a possibilidade de acompanhar práticas de professores egressos da FFP constituem outras linhas e contornos múltiplos para pensar neste currículo: esses movimentos são parte da própria experiência formativa, uma formação atravessada por aspectos que operam como linhas que ora se entrecruzam, ora se tensionam, ora se ligam, ora se opõem. Essas linhas podem ser consideradas aspectos técnicos, jurídicos, éticos, estéticos, políticos, didáticos, etc.

Percebemos que o fortalecimento e a visibilidade dos campos de estudos em diferentes "linhas" da rede formativa teve uma força expressiva a partir de 2009, coincidentemente, ano em que a maioria dos egressos participantes do Curso de Extensão começou o Curso de Pedagogia: os egressos afirmam que não apenas a disciplina obrigatória de Educação Especial contribuiu para essa aderência ao campo, mas, a participação em cursos de extensão e projetos de pesquisa, além de, a maioria, ter participado - enquanto estudante do Curso - de estágios remunerados (na função de "mediador escolar") nas redes particulares e públicas (alunos normalistas). Isso afirma a necessidade de discutirmos uma formação que se comporta como uma rede, e que inclui, tramas de fora da universidade. 
Todas estas questões estão sendo levantadas - concomitante à realização deste texto - nas discussões da Reforma Curricular do Curso de Pedagogia da FFP contemplando a Resolução $\mathrm{N}^{\circ}$ 2/2015. Consideramos que nosso estudo contribuiu para a ampliação dos estudos do campo e o reconhecimento da visibilidade das linhas formativas implicadas para uma proposta curricular que supere apenas a discussão disciplinar.

Finalmente, durante a Pesquisa e, principalmente a partir do contato com egressos e com professores participantes do Curso um analisador importante aparece e, se desdobra como um outro objeto de pesquisa: dos egressos que participaram no Curso, quatro desenvolvem funções como professores mediadores ou professores de apoio especializado ${ }^{13}$; dos trinta participantes que concluíram o Curso 16 desempenhavam a mesma função nos municípios de Itaboraí e São Gonçalo; três novos egressos se somaram aos grupos de discussão após passarem em concurso público para o cargo de professores de apoio do município de Niterói, onde já desenvolvem funções como professoras contratadas, duas alunas do Curso de Pedagogia da FFP participantes dos grupos de estudos e ex bolsistas do Sub Projeto PIBID/CAPES/UERJ do Curso de Pedagogia da FFP. Entendemos então, que, é no campo do "apoio pedagógico especializado" aonde a pesquisa aponta para um dos espaços efetivos que muitos de nossos alunos, logo formados, irão habitar e que o investimento na formação necessita apostar na problematização e abordagem dos sentidos implicados (jurídicos, didáticos, políticos, éticos e outros) nesta função, de forma tal que a Universidade responda -de forma articulada- à complexidade das demandas da escola básica.

Vários fatores podem ser registrados como avanços da pesquisa, a partir da discussão dos resultados descritos acima. Do estudo ao mergulho na experiência com a escola básica e a formação, o trabalho foi intenso e abrangente, na medida em que não se concentrou apenas em uma fonte ou em um único aspecto a ser estudado, mas se deixou afetar pelos atravessamentos inerentes ao campo de estudos.

É importante destacar como fator positivo que há um crescimento patente em termos de formação profissional dos professores e alunos envolvidos na pesquisa.

As discussões aprofundadas e as trocas com outros projetos cujos objetos de estudo atravessam o campo em investigação deixaram marcas visíveis por meio dos grupos de estudos, das

\footnotetext{
${ }^{13}$ O professor mediador - como é chamado no Município de Itaboraí - chamado de professor de apoio em São Gonçalo e com o mesmo nome em Niterói - trabalha em conjunto com o professor regente, observando as dificuldades do aluno e elaborando materiais pedagógicos que ajudem no aprendizado deste. Tem papel importante na socialização, aprendizagem e auxilia o aluno com deficiência no desempenho de suas necessidades de vida diária (Itaborai. Regimento Escolar das Unidades Escolares da Rede Pública Municipal de Ensino de Itaboraí, 2014. Sâo Gonçalo. Prefeitura Municipal de São Gonçalo Atos Oficiais. Resolução CME 01/14; e Niterói. Portaria FME 87/2011).
} 
oficinas, dos encontros e conversas, da organização e publicação de livros e artigos, da produção de monografias nas Licenciaturas dos cursos da FFP/UERJ que envolvem as temáticas da pesquisa e na produção de dissertações no âmbito do PPGedu Processos formativos e desigualdades sociais. Também a "volta" dos pedagogos egressos - para participarem como produtores do Curso de Extensão ou para cursarem o próprio Mestrado- nos mostra que há uma continuidade nos estudos e uma produção de práticas aprendidas, também, com pesquisa para o seu exercício profissional. Do ponto de vista docente, vejo professores criando dispositivos de luta em um campo árido e sem condições efetivas de estudos.

Como dizemos no ponto anterior: pensamos que o Projeto de Pesquisa numa ação articulada conseguiu implicar alguns movimentos de pesquisa o que foi o grande fator positivo produzido: por um lado, atuando na ponta, ou seja, produzindo "o chão da escola" junto com graduandos e egressos insertos, como professores, em escolas públicas que trabalham com alunos com deficiências, altas habilidades/superdotação e transtornos globais do desenvolvimento, e na produção desse chão a criação de dispositivos que permitam tensionar conceitos, instrumentos e práticas. $\quad$ Por outro lado, atuando junto com dez egressos do Curso de Pedagogia da FFP que "voltam" para discutir, a partir de suas narrativas de formação, os sentidos da proposta curricular do Curso de Pedagogia que os formou e ajudando a produzir material que subsidie as reformulações necessárias (2015/2016). Curso de pedagogia este, que está formando os alunos graduandos que participam do primeiro movimento. É importante também dizer, que desses 10 egressos, cinco voltaram também como Mestrandos em Educação do Programa de Pós Graduação, Processos Formativos e Desigualdades Sociais da FFP/UERJ com projetos de pesquisa vinculados ao campo da Educação Especial e Educação Inclusiva, ou seja, dando continuidade a um processo formativo que os produz e que eles produzem e que tem como efeito a volta do mesmo para a escola básica e a própria universidade. $\mathrm{Na}$ composição desta rede pensamos que a abertura e disponibilidade dos professores do CIEP 411 para empreender uma parceria com o Curso de Pedagogia no Sub Projeto PIBID/CAPES/UERJ acolhendo durante dois anos um projeto que discutia e produzia práticas junto a alunos com deficiências, TGD e Altas Habilidades/Superdotação foi fundamental. Pese às condições materiais de funcionamento da escola e da própria UERJ (que podemos considerar um fator negativo) conseguimos tecer espaços de estudos, analise de práticas e produção de solidariedade e parceria entre escola básica e universidade. Este ponto, e agora com relação aos pedagogos egressos, também se repete como fator positivo: os dez participantes se envolveram com o curso e as oficinas, produziram narrativas de formação e colaboraram, com elas, para a ampliação da discussão da reforma do currículo do Curso de Pedagogia, ainda em curso. Finalmente, a 
coincidência da discussão da proposta curricular com a pesquisa foi fundamental para que esta pudesse contribuir efetivamente e de forma mais atuante na reforma curricular. Neste ponto o fator tempo foi um ponto ou fator positivo da pesquisa.

Os pontos negativos do trabalho não necessariamente são considerados como limitadores da pesquisa, mas, eles se tornam (na processualidade) pistas e analisadores que nos ajudam a pensar e ampliar os sentidos que produzimos. Podemos afirmar, então, que as condições de funcionamento das escolas municipais e estaduais nas que atuamos bem como a situação pela que atravessa a UERJ, principalmente desde 2015, funcionaram como estes analisadores. Conseguimos colocar estas questões para a própria pesquisa e preservamos os espaços de discussão ainda nas greves e ocupações discutindo a formação de professores e a educação inclusiva como elementos da educação pública e como espaços de luta (através do ensino, a pesquisa e a extensão) de professores e alunos. Ao trabalhar com a proposta da cartografia como método de pesquisa operamos atentos ao que acontece e traçando novas linhas de intervenção e pesquisa na medida que o processo acontece. 


\section{BIBLIOGRAFIA}

BRAGANÇA, Inês F.S., MAURÍCIO, Lucia V. Histórias de Vida e Práticas de Formação In: (Auto)Biografia: Formação, Territórios e Saberes. Natal: EDUFRN; São Paulo: PAULUS, 2008. p. 253-271.

BRASIL. Conselho Nacional de Educação. Conselho Pleno. Parecer CNE/CP 05/2005, 13 de dezembro de 2005. Institui Diretrizes Curriculares Nacionais para o curso de graduação em Pedagogia. Encaminhado para homologação do MEC. Brasília, 2005.

CNE. Resolução 01, de 15 de maio de 2006. Institui Diretrizes Curriculares Nacionais para o Curso de Graduação em Pedagogia. Brasília, 2006.

CNE. Resolução 02, de $1^{\circ}$ de julho de 2015. Define as Diretrizes Curriculares Nacionais para a formação inicial em nível superior (cursos de licenciatura, cursos de formação pedagógica para graduados e cursos de segunda licenciatura) e para a formação continuada. Brasília, 2015.

. Lei Brasileira de Inclusão da Pessoa com Deficiência (Estatuto da Pessoa com Deficiência). Brasilia, 2015.

MEC. Nota técnica - SEESP/GAB 11/2010, 07 de maio de 2010. Orientações para a institucionalização da Oferta do Atendimento Educacional Especializado - AEE em Salas de Recursos Multifuncionais, implantadas nas escolas regulares. Brasilia, 2010.

. MEC. Política Nacional de Educação Especial na Perspectiva da Educação Inclusiva. 2008.

DELEUZE, Gilles; GUATTARI, Félix. Mil platôs: capitalismo e esquizofrenia. Trad.: Aurélio Guerra Neto; Célia Pinto Costa. Rio de janeiro: Ed. 34. 1995. vol. 1.

KASTRUP, PASSOS; ESCOSSÍA. (orgs.). Pistas do Método da Cartografia. Pesquisa-intervenção e produção de subjetividades. Porto Alegre: Sulina, 2010.

KASTRUP; PASSOS; TEDESCO. (Orgs.). Dossiê Cartografia:Pistas do Método da Cartografia. Fractal, Rev. Psicol., v. 25, n. 2, p. 217-220, maio/ago. 2013.

LARROSA, J. Tremores. Escritos sobre experiência. Belo Horizonte: Autentica: 2014.

PLETSCH, M. D. Repensando a inclusão escolar: diretrizes políticas, práticas curriculares e deficiência intelectual. Rio de Janeiro: NAU/EDUR, 2010.

SKLIAR, Carlos. Seis perguntas sobre a questão da inclusão ou de como acabar de uma vez por todas com as velhas - e novas - fronteiras em educação. Revista Pro-posições, v. 12, n. 2-3 (35-36), jul./ nov. 2011. 


\section{RESUMO}

Este texto tem como finalidade apresentar resultados do Projeto de Pesquisa que leva o nome do artigo e que teve três objetivos: primeiro, analisar o currículo do Curso de Pedagogia da FFP da UERJ e problematizar as lógicas e sentidos produzidos pelo mesmo com referência ao campo da Educação Especial na Formação dos Professores, especificamente dos pedagogos. Segundo, cartografar práticas de professores egressos do mesmo Curso que trabalhassem em escolas regulares com alunos com deficiências para tornar visível e enunciar os efeitos e experiências que relacionam a formação inicial e continuada com os desafios da inclusão no cotidiano escolar. O terceiro objetivo foi analisar e intervir no processo formativo de alunos que participaram do Subprojeto PIBID/CAPES/UERJ do Curso de Pedagogia da FFP, através dos projetos direcionados ao estudo das diferenças em educação tensionando os achados de pesquisa de campo com elementos teóricos e políticos do próprio Curso.

Palavras-chave: educação especial; formação de professores;curso de pedagogia.

\section{TENSIONS BETWEEN POLITICS, CURRICULUMS AND INCLUSIVE EXPERIENCES IN THE TRAINING OF TEACHERS IN SÃO GONÇALO \\ ABSTRACT}

This text aims to show the results that state the effects of the Research Project "Tensions between Politics and Inclusive Experiences in Teacher Training in São Gonçalo" The research had three main objectives. The first was to analyze the curriculum of the Pedagogy Course of the Faculty of Teacher Training (FFP) of the UERJ after the year 2006 and to problematize the logics and meanings produced by it with reference to the field of Special Education in Teacher Training, specifically of pedagogues. The second objective was to map practices of teachers from the same Course who worked in regular schools with students with disabilities, global developmental disorders and high skills / gifting, in São Gonçalo (RJ) to make visible and state the effects and experiences Which relate initial and continuing formation to the challenges of inclusion in school daily life. The third objective was to analyze and intervene in the formative process of students who participated in the PIBID / CAPES / UERJ Subproject of the Pedagogy Course of FFP, through the projects directed to the study of differences in education and policies and / or practices of school inclusion, stressing the findings of field research with theoretical and political elements of the Course itself.

Keywords: Special education; teacher training; Pedagogy course.

Submetido em Nov./2016

Aceito em Jul./ 2017

Revista Teias v. 18, n. 50, 2017 (Jul./Set.): Conversas sobre formação de professores, práticas e currículos 